\title{
A Emergência das Noções de Formação, Livro Didático e Ambiental na Educação em Ciências
}

\section{The Emergence of the Notions of Training, Textbook and Environment in Science Education}

\author{
Samuel Molina Schnorr ${ }^{1}$ \\ iD Maurício Pietrocola ${ }^{1}$

\begin{abstract}
'Universidade de São Paulo (USP), Faculdade de Educação, São Paulo, SP, Brasil. Autor correspondente: schnorr.sm@gmail.com
\end{abstract}

Resumo: Nesta investigação analisamos a emergência dos mecanismos discursivos e argumentativos utilizados por pesquisadores brasileiros para abordar as noções de formação, livro didático e ambiental em artigos de educação em ciências publicados nos últimos 25 anos (1994-2018). A partir de um banco de dados com 3014 artigos que abordam o ensino de ciências, selecionamos os textos que continham uma dessas noções. Construímos redes semânticas a partir de ferramentas da análise do discurso para selecionar 10 textos de cada noção (30 no total), a partir das unidades com maior frequência. Os resultados indicaram a existência de um estranhamento no discurso dos pesquisadores, como se cotejassem o papel da pedagogia na educação em ciências. As pesquisas analisadas sugerem um enfrentamento a uma visão cientificista da área e uma ausência dos saberes educacionais em temáticas do ensino de ciências. As problematizações que estão sendo adicionadas na área pelos pesquisadores são influenciadas, sobretudo, pela presença do discurso pedagógico.

Palavras-chave: Educação ambiental; Livro didático; Conhecimento científico; Conhecimento pedagógico; Revisão de literatura.

Abstract: In this investigation we analyze the emergence of discursive and argumentative mechanisms used by researchers to address the notions of training, textbook and environment in science education articles published in the last 25 years (1994-2018). The texts were selected from a database of 3014 articles that address science education. We built semantic networks using discourse analysis tools to select 10 texts from each notion (30 in total), from the most frequent units. The results indicated the existence of strangeness in the researchers' discourse, as if they measured the role of pedagogy in science education. The review of the studies suggest a confrontation with a scientific view of the area, and an absence of educational knowledge on science teaching themes. Therefore, the problems that are being added to the area by the researchers are influenced, above all, by the presence of the pedagogical discourse.

Keywords: Environmental education; Textbook; Scientific knowledge; Pedagogical knowledge; Bibliographic research.

Recebido em: 02/07/2020

Aprovado em: 19/03/2021 


\section{Introdução e contexto da pesquisa}

Em uma dada área do conhecimento, como a educação em ciências, alguns temas se tornaram predominantes ao longo dos anos e outros ganharam uma menor atenção analítica. Essa ênfase maior em temas específicos está atrelada aos processos históricos, sociais e políticos de cada sociedade e, portanto, se destacam entre a comunidade e a pesquisa científica. De acordo com Bourdieu (2004, p. 25), "[...] os pesquisadores ou as pesquisas dominantes definem o que é, num dado momento do tempo o conjunto de questões que importam para os pesquisadores, determinando uma concentração de esforços de pesquisa".

Esta investigação parte dos resultados de uma pesquisa que teve como objetivo caracterizar e analisar as práticas da educação em ciências nos últimos 25 anos (SCHNORR, 2019). O material empírico desse estudo recobre a produção, entre 1994 e 2018, dos 10 periódicos brasileiros de educação em ciências mais bem avaliados pela Coordenação de Aperfeiçoamento de Pessoal de Nível Superior (CAPES). Foram selecionados 3014 artigos classificados como produção nacional e que abordam o ensino de ciências. O conteúdo desses artigos foi analisado com base em diferentes variáveis, dentre elas a frequência de palavras nos títulos, resumos e palavras-chave. Como resultado dessa análise textual, três noções se destacaram como focos de interesse dos pesquisadores: formação, livro didático e ambiental (SCHNORR, 2019). Essas três noções são frequentemente utilizadas pelos autores nos títulos, resumos e palavras-chave dos 3014 artigos analisados nos últimos 25 anos de pesquisa em educação em ciências no Brasil. Entendemos que essas noções são representativas para a área ao sinalizar uma emergência investigativa em torno delas, bem como temas que se destacaram ao longo dos anos. Seguindo essa linha analítica, exploramos essas noções a partir do banco de dados criado na categorização geral dos 3014 artigos. Para isso, resolvemos focar nos textos que tratam dessas três noções, justamente para entender a importância e o sentido que elas denotam para a área, haja visto sua elevada frequência nos artigos. Portanto, o objetivo desta pesquisa é analisar a emergência dos mecanismos discursivos e argumentativos utilizados por pesquisadores para abordar as noções de formação, livro didático e ambiental em artigos de educação em ciências publicados nos últimos 25 anos (1994-2018).

Consideramos as pesquisas em ensino de ciências como práticas discursivas que constituem a área, a partir de conhecimentos que ocupam espaços e tempos específicos (FOUCAULT, 2013). De acordo com o autor, é pelo discurso que as relações de saber e poder se formam. Nesse ínterim, entendemos que para pensar as práticas do ensino de ciências podemos analisar os discursos dos pesquisadores que constituem um modo de ensinar ciências e são veiculados em revistas científicas. Logo, a educação em ciências pode ser compreendida como produtora de discursos que estabelecem e validam saberes, pois se aproxima da constituição de uma ordem do discurso (FOUCAULT, 2012). O autor afirma que existe um limiar de cientificidade ao qual somente alguns discursos chegam e que uma positividade reforçaria essas práticas dentro de um regime que os acolhe e os faz funcionar como verdadeiros. A recorrência dessas três noções no discurso dos pesquisadores reforça a necessidade de analisar esses discursos para entender de que modo a área vem se constituindo e se centralizando em algumas problemáticas. Portanto, esta pesquisa visa aprofundar a análise a partir da imersão nos textos que 
tratam dessas três noções, com a intenção de problematizar a presença recorrente desses termos no discurso dos pesquisadores da área e os efeitos dessas noções para pensar as práticas da educação em ciências.

\section{Percursos metodológicos}

Escolhemos para a análise as publicações científicas, pois entendemos que a partir dessas fontes podem emergir discursos e práticas utilizadas em uma área, bem como abordagens teóricas e empíricas relacionadas a um determinado período. Como a maioria dos manuscritos atualmente é revisada por pares antes da publicação, as revistas científicas são uma fonte válida de informação reconhecida pela comunidade científica. Assim, escolhemos as revistas com melhor avaliação e que estão classificadas na área de Ensino do Qualis-CAPES. Essa área concentra revistas que abordam conhecimento pedagógico e conteúdo disciplinar (por exemplo, biologia e química) e que tratam do ensino de ciências no Brasil (conforme descrição no título ou escopo da revista). Os 10 periódicos selecionados foram: Revista Brasileira de Ensino de Física, Caderno Brasileiro de Ensino de Física, Bolema: Boletim de Educação Matemática, Química Nova na Escola, Investigações em Ensino de Ciências, Ciência \& Ensino, Ciência \& Educação, Ensaio: Pesquisa em Educação em Ciências, Acta Scientiae: Revista de Ensino de Ciências e Matemática, e Revista Brasileira de Pesquisa em Educação em Ciências. Selecionamos essas 10 revistas porque concentram os estudos mais bem avaliados e repercutem as ideias de pesquisadores e professores do ensino de ciências do país. Igualmente, apresentam temas, teorias e conceitos que tiveram grande impacto nas pesquisas da área nos últimos anos.

Avaliamos todos os artigos publicados nessas 10 revistas entre 1994 e 2018 . Esse intervalo foi escolhido para garantir a robustez dos dados, considerando que, dentre as revistas selecionadas, sete publicaram pela primeira vez em 1994 ou posteriormente. Analisamos os artigos pelos títulos, resumos e palavras-chave, e selecionamos apenas aqueles que abordavam o ensino de ciências. Não selecionamos, por exemplo, publicações focadas na discussão de conceitos teóricos ou entrevistas, bem como publicações estrangeiras. Encontramos 3014 artigos nos periódicos analisados que tratavam do ensino de ciências, classificados como produção nacional. Esse volume de artigos constituiu o nosso banco de dados que foi utilizado tanto para fazer uma análise mais geral da área (SCHNORR, 2019) quanto serviu como fonte empírica para esta investigação.

Dentre os 3014 textos, selecionamos os artigos em que apareciam, pelo menos uma vez, uma das três palavras (formação, livro didático e ambiental) no título ou no resumo. Essa ação foi feita separadamente para cada um dos termos. Para essa seleção não foram considerados a revista, o ano, os autores e nem qualquer outro metadado identitário relativo ao artigo. Construímos redes semânticas para cada uma dessas noções, com o auxílio do software Rstudio (R CORE TEAM, 2018). As redes são sistemas de representação do conhecimento baseados em grafos, cujos vértices são palavras e as arestas as conexões entre as palavras estabelecidos por algum princípio (ROSA, 2016). A regra que determinamos para construção da rede foi a incidência/força-fidelidade, um índice que está associado, de acordo com Teixeira et al. (2010), à frequência com que um determinado par de palavras é evocado no discurso escrito. Para gerar uma lista com os 
pares de palavras mais utilizados empregamos os seguintes critérios: (i) diagramação e adequação dos títulos e resumos para análise no programa Rstudio (junção de títulos e resumos, como uma sequência textual); (ii) executar o comando para gerar as relações (arestas) entre as palavras (vértices) um a um (isto é, palavra1-palavra2; palavra2palavra3; e assim consecutivamente); (iii) quanto maior a incidência-fidelidade, menor o número de pares de palavras. Portanto, permaneceram na rede apenas os pares que têm valores iguais ou maiores que uma incidência-fidelidade pré-determinada, que foi diferente para cada noção, devido ao número de artigos analisados. As redes são formadas por uma estrutura de nós, representando as palavras, ligadas por setas que demonstram as relações e o sentido dessas palavras no texto, bem como por unidades semânticas (caracterizadas pelo agrupamento de no mínimo duas palavras). As redes semânticas, nesta pesquisa, oferecem uma visão geral sobre as noções e sua utilização pelos pesquisadores da educação em ciências. Utilizamos as redes como ponto de partida para uma investigação mais detalhada dos artigos que compõe o nosso banco de dados. A partir das redes de cada noção e as unidades com maior frequência, selecionamos trinta textos para fazer uma análise mais aprofundada.

Construímos, também, uma ferramenta analítica inspirada na análise do discurso (FOUCAULT, 2012, 2013), que foi usada para as três noções investigadas, na qual delineamos: (i) os excertos do texto que concentram o discurso dos autores sobre uma noção; (ii) as categorias que são utilizadas para falar sobre; (iii) as subcategorias que auxiliam nesse empreendimento e, (iv) as nossas descrições sobre os usos dessas noções em cada artigo. Essa ferramenta foi utilizada para direcionar o nosso olhar e ressaltar os mecanismos discursivos e argumentativos dos quais os autores se valem para tratar das noções investigadas. A partir da análise discursiva na perspectiva foucaultiana, descrevemos as condições de existência dos discursos dos pesquisadores sobre as noções investigadas, entendo-os como práticas que representam à educação em ciências. O nosso interesse incidiu sobre os conjuntos de enunciados que se relacionam e assumem uma organização (as redes semânticas expressam esse arranjo), pois fazem parte de uma mesma ordem discursiva. Realizamos a descrição das práticas que estão presentes nos artigos e mostramos algumas formações discursivas que compõe o ensino de ciências. A análise dos textos possibilitou gerar unidades de sentido sobre as três noções e encontrar pontos de convergência no discurso dos pesquisadores que formaram uma rede argumentativa sobre cada noção.

\section{Resultados e discussão}

Encontramos a palavra formação em 934 artigos, ambiental em 154, e livro didático em 221. A partir desses artigos construímos as redes semânticas respeitando a regra incidência/força-fidelidade para cada noção (figura 1). Com isso, atentamos para a armação argumentativa em torno das noções que representam uma regularidade discursiva para a área, conforme o objetivo da pesquisa. 
Figura 1 - Redes semânticas das noções formação (A), livro didático (B) e ambiental (C), demonstrando os termos mais frequentes e as relações entre eles

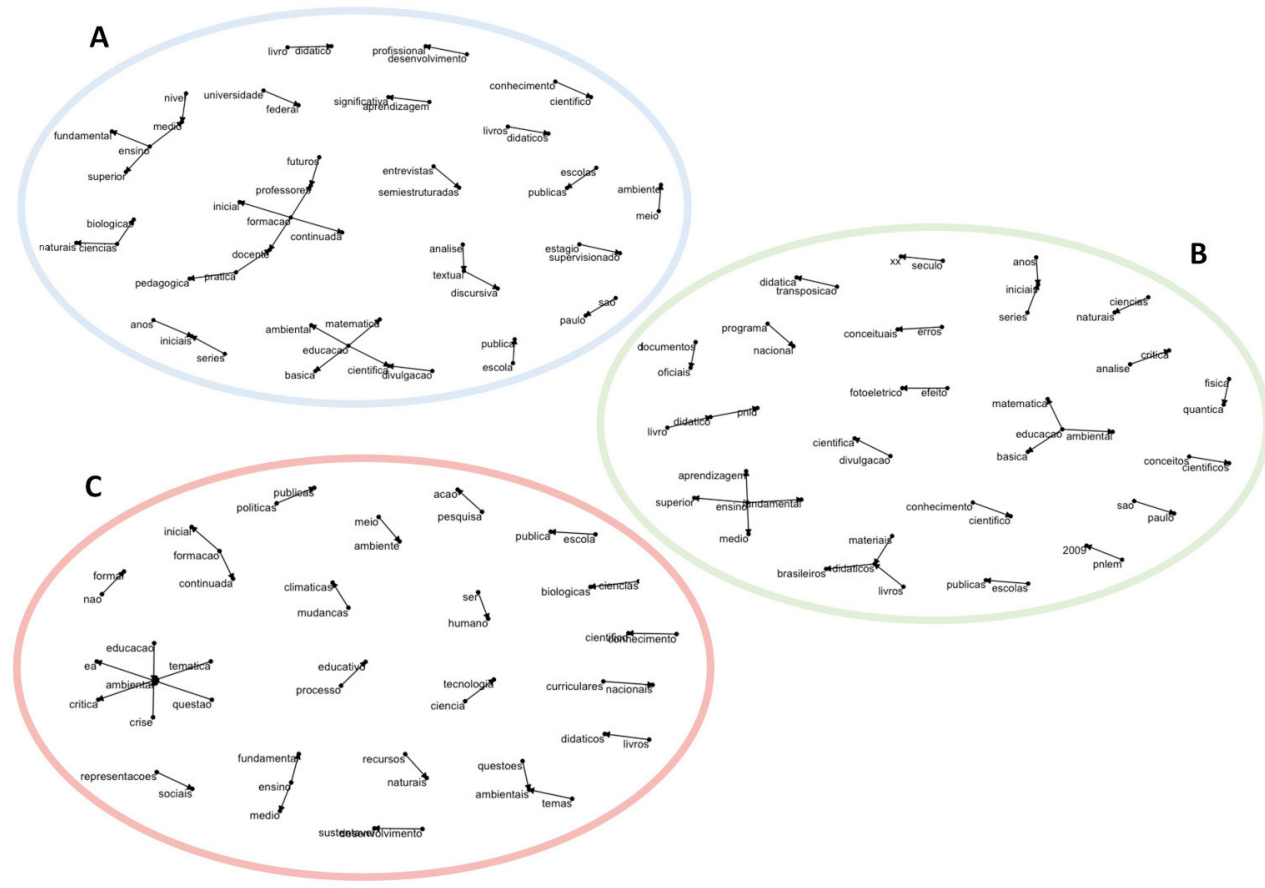

Fonte: elaborado pelos autores.

Realizamos a seleção dos textos a partir das unidades semânticas mais frequentes nas redes. Fizemos a leitura dos títulos e resumos dos textos e selecionamos os trinta que incluíam os termos mais frequentes. Para formação os termos utilizados para selecionar os artigos foram: formação, professores, docente, inicial e continuada. Com livro didático: PNLD e brasileiros. Para ambiental: educação, temática e crítica. Os dez artigos selecionados para cada uma das noções constituíram a fonte empírica em que nos baseamos para fazer essa análise mais aprofundada (quadro 1). Primeiramente, abordamos a noção de formação, depois livro didático e por último ambiental.

Quadro 1 - Os trinta artigos selecionados que tratam das noções de formação, livro didático e ambiental dentre os 3014 textos da área de educação em ciências

\begin{tabular}{|l|l|}
\hline \multicolumn{1}{|c|}{ Noções } & \multicolumn{1}{c|}{ Textos analisados } \\
\hline Formação & $\begin{array}{l}\text { Abib; Murillo; Lourenço (2016); Christino; Ferreira (2013); Cruz; Barzano (2014); Fiorentini (2008); } \\
\text { Magalhães Júnior; Tomanik; Carvalho (2016); Massena; Siqueira (2016); Silva; Chaves (2009); } \\
\text { Silveira (2004); Vianna; Carvalho (2001); Villani et al. (2017). }\end{array}$ \\
\hline Livro didático & $\begin{array}{l}\text { Braga; Mortimer (2003); Gramowski; Delizoicov; Maestrelli (2017); Lima; Ostermann; Cavalcanti } \\
\text { (2017); Nicioli Junior; Mattos (2016); Oliveira; Rosa (2016); Reis; Albuquerque; Soares (2014); } \\
\text { Schirmer; Sauerwein (2017); Selles; Ferreira (2004); Vilanova (2015); Zambon; Terrazzan (2017). }\end{array}$ \\
\hline Ambiental & $\begin{array}{l}\text { Cavalcanti Neto; Amaral (2011); Cosenza et al. (2014); Costa; Loureiro (2015); Costa; Echeverría; } \\
\text { Ribeiro (2017); Cunha; Latini (2014); Loureiro; Lima (2009); Lucatto; Talamoni (2007); Morozesk; } \\
\text { Coelho (2016); Pasin; Bozelli (2017); Valdanha Neto; Kawasaki (2015). }\end{array}$ \\
\hline
\end{tabular}

Fonte: elaborado pelos autores.

\section{A marginalização dos saberes pedagógicos na formação de professores de ciências}

A análise dos dez artigos mostrou que existe uma emergência discursiva diagnosticando uma formação inicial insuficiente de professores em ciências: "o aluno da licenciatura não possui uma boa formação"; "não está preparado para enfrentar a 
escola"; "o tempo formativo é impróprio"; "existe uma escola ideal, que é diferente da escola real"; "a universidade não dialoga com a escola" (enunciados encontrados nos textos). Além disso, destacamos algumas propostas que entendemos como práticas para mitigar essa insuficiência, como os mestrados profissionais e os programas de incentivo à docência (VILLANI et al., 2017). A constituição de uma identidade professoral é uma preocupação constante e representa uma emergência para a área. Os pesquisadores Fiorentini (2008), Christino e Ferreira (2013) indicam que a entrada dos alunos/estagiários na sala de aula traz outras perspectivas do que é ser professor e especificidades da profissão. Eles tratam esse momento como um "tratamento de choque", pois ocorrem muitos conflitos entre diferentes ideias advindas da universidade e da escola, bem como as especificidades da área de ciências (CHRISTINO; FERREIRA, 2013).

O licenciando em ciências tem muitas dúvidas sobre o seu futuro profissional, elas aumentam quando ele tem contato com a escola ou com atribuições professorais (MAGALHÃES JÚNIOR; TOMANIK; CARVALHO, 2016). Somado a isso, as pesquisas analisadas identificam um desprestígio com a formação de professores e uma "valorização"das atividades de pesquisa, própria da área de ciências (SILVEIRA, 2004). Esse conflito só ocorre porque o aluno está em constante contato com as disciplinas de conhecimento específico que, invariavelmente, não possuem um viés para atuação na escola: "[...] a formação do futuro professor não condiz com o exercício de sua profissão, ou seja, teoria e prática não dialogam" (MASSENA; SIQUEIRA, 2016, p. 23). Resulta que o licenciando está sempre perspectivando seu futuro profissional a partir de uma carreira como bacharel ou licenciado. Essa escolha é uma característica da área de ciências e, de acordo com os autores, há um caminho preconizado a ser seguido: "[...] ainda hoje, em cursos de Ciência há uma maior valorização para a formação de bacharéis, sendo visto como menor a opção de exercício da docência na educação básica" (CHRISTINO; FERREIRA, 2013, p. 173).

O tempo de formação é destacado como algo fundamental: o sucesso da formação está atrelado a mais tempo formativo (MAGALHÃES JÚNIOR; TOMANIK; CARVALHO, 2016; SILVEIRA, 2004). Os textos analisados denunciam modelos diferentes em voga na formação de professores, em que o tempo é uma variável em disputa: um modelo neoliberal visando uma economia e os resultados em pouco tempo e outro, que priorizaria o tempo e a qualidade como requisito: "[...] o curso de formação deveria ter, ao invés de três anos como vem ocorrendo atualmente, uma duração de no mínimo cinco anos" (FIORENTINI, 2008, p. 48). Acreditamos que essa disputa, para além dos meandros políticos associados à essas perspectivas, reúne um mecanismo discursivo com relação a uma formação idealizada: quanto mais tempo o aluno passar vinculado à universidade melhor será a sua atuação profissional. Nesse caso, a variável tempo agiria em prol da universidade, que encontra nessa argumentação uma defesa contra o discurso da formação de professores deficitária, de ser considerada distante das necessidades da sociedade e de uma política que a restringiria como espaço formativo.

Essa eloquência com relação ao tempo dá sinais de uma formação que nunca acaba, um sujeito que está sempre em desenvolvimento. O futuro professor nunca está pronto para o por vir e precisa permanecer em constante supervisão e acompanhamento da universidade: "[...] o trabalho de acompanhar professores principiantes constitui uma importante oportunidade para nutrir a formação inicial" 
(CHRISTINO; FERREIRA, 2013, p. 177). Entretanto, a universidade, de acordo com os nossos dados, não cumpre sua função formativa, pois não acompanha as necessidades dos futuros professores, seus anseios e as exigências profissionais da escola (SILVEIRA, 2004; VILLANI et al., 2017). "Assume-se assim, que a formação recebida pelos licenciandos na universidade apresenta deficiências e isso resulta em professores mal preparados para as exigências mínimas da profissão" (MASSENA; SIQUEIRA, 2016, p. 22). Por um lado, há uma argumentação a favor de uma maior carga horária e de um acompanhamento maior para aprimorar a formação inicial de professores, por outro há uma universidade que não está formando o profissional que a escola precisa. Existe um discurso que identifica as insuficiências dessa formação a partir de duas instituições que não estão de acordo e seriam responsáveis por esses problemas: universidade e escola. O que acontece na escola não reflete na formação universitária, e nem o contrário. Acreditamos que a dinâmica própria da educação em ciências ampliaria essa problemática, pois aborda o conhecimento científico distante do pedagógico. Fica evidente, em nossa análise, que um dos problemas fundamentais na formação de professores em ciências no Brasil é que estes são formados num modelo científico, que privilegia o conteúdo e o conceito em detrimento dos saberes pedagógicos necessários para a prática professoral.

O que se antevê é uma estreita relação entre o modo como se pensa e se ensina ciência (SILVEIRA, 2004). Nesse sentido, encontramos na formação de professores uma direção que mostra como os saberes científicos se sobressaem aos pedagógicos, corroborado pelas insuficiências apontadas pelos artigos analisados e pela relação que a universidade, espaço de formação por excelência, possui com esses conhecimentos. Outras problemáticas a serem consideradas são a ocorrência de uma aprendizagem pela experiência e da escolha do professor em adotar um modelo de ensino reprodutivista, inspirado nas práticas com as quais ele teve contato enquanto aluno da educação básica e superior: "Consideramos [na formação de professores] que existam essas duas possibilidades ou até mesmo que elas estejam imbricadas: a autodidata e a reprodução das práticas dos professores de suas trajetórias - os professores ensinam como aprenderam" (CRUZ; BARZANO, 2014, p. 118). O aprender pela experiência autodidata estaria vinculado aos problemas que a universidade possui para formar professores e a relação que estes estabelecem quando entram em sala de aula pela primeira vez. Quer dizer, o professor se forma menos pelo curso de licenciatura e mais pela sua prática inicial, pelas experiências que ele tem como aluno e professor, bem como pela interação com outros, sejam eles colegas de profissão ou seus próprios professores do ensino superior. Os pesquisadores Massena e Siqueira (2016, p. 23), inclusive, afirmam que nos cursos de licenciatura o que ocorre é um "despreparo da docência".

É possível identificar um paradoxo na formação de professores em ciências: olugar de formar professores para a educação básica também é o que o professor universitário é formado. Essa contradição mostra como o saber para docência é secundarizado, pois o próprio professor formador, especialmente o das disciplinas específicas, não possui ou acaba desenvolvendo esse saber pela experiência acumulada, como um autodidata (CRUZ; BARZANO, 2014). Isso faz com que, na formação de professores, seja mais factível ensinar ciências do que ensinar como se ensina ciências. Decorre, portanto, uma marginalização dos saberes pedagógicos na formação de professores 
de ciências. Outra dimensão a ser considerada é o modelo da pós-graduação brasileira, que privilegia a pesquisa e uma consideração quase nula com a docência no ensino superior (VIANNA; CARVALHO, 2001, p. 131).

Conforme os artigos analisados, foi possível identificar uma hegemonia dos saberes científicos na formação de professores. Os saberes pedagógicos estão relegados, nessa formação, ao aprender fazendo, pela experiência, sem atentar para as discussões que já são realizadas pela área de pesquisa em educação em ciências. 0 que fortalece o argumento da marginalização desses saberes no desenvolvimento dos professores de ciências.

Isso nos faz supor que os saberes pedagógicos ocupam um lugar menor no campo. A formação inicial acadêmica tem valor 'fundante' na profissionalização docente e, se foram silenciados/negados saberes pedagógicos nessa formação, a atuação profissional será marcada também por esse/a silêncio/negação. (CRUZ; BARZANO, 2014, p. 135).

Conforme indicam os discursos dos pesquisadores da educação em ciências, a formação de professores não está ocorrendo na universidade, embora seja esse o espaço institucionalizado para tal. Posto que ocorra uma formação, ela não se coaduna com o que a escola indica como necessário e os próprios alunos/estagiários relatam essa diferenciação (CRUZ; BARZANO, 2014). Portanto, se a formação de iniciação à docência não está ocorrendo na universidade, a escola estaria formando esses professores? A aprendizagem pelas experiências em sala de aula (MAGALHÃES JÚNIOR; TOMANIK; CARVALHO, 2016), o professor que faz sua própria aprendizagem (VILLANI et al., 2017), pela relação com outros professores (SILVEIRA, 2004) e a dissociação entre o que a universidade ensina e o que a escola precisa (CRUZ; BARZANO, 2014) recomendam uma resposta positiva a essa pergunta.

Os pesquisadores da área, sabendo desses problemas relacionados à formação, propõem algumas ações para diminuí-los, dentre elas a reflexão sobre a própria prática e a tomada de consciência. Entendemos que essas propostas são noções-chave para a área, devido à frequência que surgem no discurso dos autores analisados: "[...] é preciso que nosso docente, numa atividade de atualização, possa refletir sobre a sua prática, os conteúdos que ensina, aprendendo o que acaba de ser produzido, colocando-o em xeque em como introduzir os novos conhecimentos em sala de aula." (VIANNA; CARVALHO, 2001, p. 115).

O que percebemos é que essa "atualização docente" acontece somente na formação continuada, nos mestrados profissionais ou com programas governamentais voltados à licenciatura, especificamente o Programa Institucional de Bolsas de Iniciação à Docência (PIBID) (MAGALHÃES JÚNIOR; TOMANIK; CARVALHO, 2016; VILLANI et al., 2017). Os autores não assinalam essa atualização voltada à formação inicial. Visto que os problemas já foram identificados, a reflexão e a tomada de consciência são práticas que poderiam ocorrer também nesse momento. A escola e a universidade não dialogam no que tange à formação de professores, o que é apontado pelos autores como uma das causas da formação insuficiente dos docentes. Entendemos que a escola e a universidade são instituições distintas, com culturas diferentes. Logo, a aproximação entre escola e universidade não significa, necessariamente, uma melhoria para a formação de professores. A formação continuada estaria nessa mesma 
lógica: se a universidade voltar a ter contato com o professor, que agora já possui uma experiência mais significativa de sala de aula, também não vai implicar em uma melhora na atuação desse professor, ainda mais enraizado na cultura escolar.

Observamos uma marginalização dos saberes pedagógicos na formação inicial de professores de ciências. Por outro lado, a formação continuada seria um momento em que o professor tem contato com esses saberes, considerando-o, agora, conhecedor da prática escolar. Isso é o que os autores conceituam como "ressignificação", tanto da identidade docente, quanto do papel ocupado pela escola nessa formação (MASSENA; SIQUEIRA, 2016; SILVA; CHAVES, 2009). Esse novo significado seria um dos efeitos de uma relação não hierarquizada entre os saberes científicos e pedagógicos. Acreditamos que a idealização dos mestrados profissionais e do PIBID tenta mitigar essa diferença entre os saberes que compõem a carreira dos professores de ciências, o que atesta a secundarização de um referencial pedagógico silenciado na formação. Para fazer isso, os mestrados profissionais focam suas atividades nos professores das redes de ensino público e privado que, além da dissertação, entregam um produto de natureza educacional, aplicado e testado em sala de aula. Essas particularidades inserem o mestrado acadêmico em um escopo diferente no processo de formação, de acordo com Villani et al. (2017). Já o PIBID "[...] tem buscado uma maior articulação universidade-escola, contribuindo para superação do hiato existente, muitas vezes, entre essas duas instituições de ensino" (MASSENA; SIQUEIRA, 2016, p. 19).

O mecanismo discursivo, em voga nos artigos analisados, de aproximar teoria (universidade) e prática (escola) para uma melhora na formação, contrasta com a ideia de que universidade e escola não conseguem dialogar. A universidade está tratando mais da formação científica dos alunos e a escola de uma pedagogia de ensino, sustentada pelas experiências em sala de aula e pela relação com outros docentes. Portanto, não teríamos os efeitos desejados nessa aproximação entre universidade e escola, teoria e prática, porque cada instituição construiu sua própria teoria e prática, legitimadas e atreladas às especificidades de cada espaço.

\section{Livros didáticos: da mediação de saberes à uma pedagogia para ensinar}

A leitura dirigida dos dez artigos que tratam do Livro Didático (LD) reforça a tese de que existe um modelo para essas pesquisas: os pesquisadores avaliam o seu conteúdo e usos, bem como a forma como é feita a seleção pelo Programa Nacional do Livro e do Material Didático (PNLD), e as políticas educacionais para os LD. Grande parte dessas análises são desaprovações: "[...] o livro didático de ciências vem sendo alvo, há muitos anos, de uma série de críticas" (VILANOVA, 2015, p. 180). "Essa investigação surge a partir da constatação dos inúmeros problemas que envolvem os livros didáticos de ciências: a existência de inúmeros erros conceituais e as formas de representações" (SELLES; FERREIRA, 2004, p. 102). Essas críticas são baseadas, principalmente, em cinco pontos: (i) por sua estrutura, os LD apresentam uma visão fragmentada do conhecimento (GRAMOWSKI; DELIZOICOV; MAESTRELLI, 2017); (ii) fortalecem uma proposta de memorização dos conteúdos científicos (ZAMBON; TERRAZZAN, 2017); (iii) demonstram uma abordagem empirista e indutivistas da ciência (VILANOVA, 2015); (iv) na avaliação dos pesquisadores, os LD não se relacionam com as exigências da educação e com as pesquisas em ensino, estariam descontextualizados 
(LIMA; OSTERMANN; CAVALCANTI, 2017), e (v) são subutilizados pelos professores (REIS; ALBUQUERQUE; SOARES, 2014). Podemos observar que esses pontos estão conectados aos usos e às relações de ensino e aprendizagem presentes nos LD. Ainda que esses problemas estejam descritos, o discurso dos pesquisadores é baseado na ideia de que o LD é um componente que estrutura a educação escolar: "[...] os LD têm sido, ao longo de nossa tradição cultural, um poderoso instrumento de seleção e organização dos conteúdos e métodos de ensino" (SELLES; FERREIRA, 2004, p. 103). Essa relação entre um material que fundamenta a prática escolar e os diferentes problemas que o cercam colocam o LD em constante avaliação. Para além disso, o LD materializa diferentes perspectivas educacionais e projetos políticos, bem como um encontro dos discursos pedagógico e científico.

Os pesquisadores mostram que existe uma crescente dependência dos LD: "[...] um número cada vez maior de professores encontrou nesses materiais um colaborador silencioso que definia a seleção e organização tanto dos conteúdos quanto das atividades e métodos de ensino" (SELLES; FERREIRA, 2004, p. 103). Essa dependência, na visão dos autores, se configura em um problema quando o professor usa o LD como o único recurso nas aulas, o que interfere diretamente nas decisões do docente quanto à seleção dos conteúdos a serem ensinados e os melhores meios para tal. Essa situação coloca o LD como um dos elementos que corroboram e reproduzem os principais problemas educacionais, como a memorização (REIS; ALBUQUERQUE; SOARES, 2014). Portanto, existe um discurso que atribui a padronização de um modelo de ensino e dos conteúdos ao LD. Se existe essa dependência, ela ocupa um destaque na prática dos professores e, devido à abrangência que o material possui nas escolas brasileiras, determinaria o que é ensinado e aprendido. Essa é uma argumentação recorrente na análise sobre os usos do LD nas escolas de educação básica (OLIVEIRA; ROSA, 2016; VILANOVA, 2015). Observamos uma relação entre as insuficiências na formação inicial de professores, já destacadas na seção anterior, e a dependência do LD. Os pesquisadores abordaram essa associação como uma possibilidade de o professor conseguir alguma sustentação na prática inicial em sala de aula. A lógica nesse pensamento demonstra um acordo tácito: uma formação inicial que não é significativa para a prática do futuro professor faz ele buscar no LD uma sustentação necessária para a realização das suas atividades.

Podemos observar que existe um certo "modo de ensinar" que se estabeleceria pela experiência do próprio professor e pelos estruturantes da cultura escolar. Sua atuação em sala de aula, portanto, refletiria "uma tradição já naturalizada" (ZAMBON; TERRAZZAN, 2017, p. 14). Contudo, os pesquisadores argumentam que o professor não fica atrelado ao LD, mas a esse modo tradicional de dar aula, ainda que o livro seja considerado um componente desse formato. Logo, o LD não é substancial para modificar essa tradição naturalizada de ensinar. Os autores avaliam que esse é o motivo do descompasso entre a inovação trazida pelo LD, por meio do PNLD, e a manutenção desse formato tradicional, mesmo após anos de existência do programa (BRAGA; MORTIMER, 2003; NICIOLI JUNIOR; MATTOS, 2016). De acordo com essa argumentação, alguns elementos dos LD são absorvidos pelos professores em suas práticas, desde que não descaracterizem esse modelo de ensino reconhecido na cultura escolar. Dentre esses elementos estariam: a disposição dos conteúdos, organizados e selecionados; a manutenção de um certo conhecimento, desconsiderando as inovações ou descobertas 
científicas; os exercícios, que reforçam os conceitos e ajudam a memorizar; a consulta pontual de textos e a apresentação de imagens ilustrativas (REIS; ALBUQUERQUE; SOARES, 2014; SCHIRMER; SAUERWEIN, 2017). Assim, esses recursos do LD são utilizados para reproduzir uma prática já consolidada do professor e desenvolver seus saberes da experiência, consolidando uma pedagogia do ensino.

O que percebemos, nos discursos dos pesquisadores, é que os professores utilizam o LD como principal mediador em sala de aula, contudo não ocorrem transformações mais amplas em suas práticas, subutilizando esse material. Quer dizer, o uso do LD está, diferentemente do idealizado no programa, mantendo uma "forma habitual de desenvolvimento das aulas" (ZAMBON; TERRAZZAN, 2017, p. 19). O LD está presente em um contexto amplo que inclui a formação de professores, cultura escolar, políticas públicas, autoria e seleção dos LD. Nesse sentido, observamos que existe uma preocupação dos pesquisadores em avaliar os usos do LD pelos professores e os conteúdos científicos presentes nesse material. Entretanto, o livro é considerado, muitas vezes, como um objeto isolado e impermeável às análises mais contextualizadas.

Os resultados que discutimos na seção anterior também indicavam que a formação acadêmica tinha uma menor influência na atuação do professor. Entendemos que isso ocorre em função da marginalização dos conhecimentos pedagógicos e das diferenças entre universidade e escola. Assim, quanto maior a experiência do professor em sala de aula mais uso ele faz dos recursos disponíveis, ainda que - LD permaneça sendo subutilizado e fonte de uma pedagogia para ensinar. Nesse sentido, "[...] podemos dizer que os livros didáticos têm-se apropriado de discursos tanto do campo científico quanto do educacional" (SELLES; FERREIRA, 2004, p. 103). Na perspectiva dos pesquisadores o LD materializa o encontro desses dois discursos: científico e educacional. Assim, esse material didático é considerado como um elemento mediador dos diferentes saberes que compõe a educação em ciências. $O$ LD parece estar influenciando diretamente a relação entre universidade e escola, servindo como uma sustentação para uma formação insuficiente e complementando, junto com a escola, a função formativa de uma pedagogia para ensinar. Encontramos pistas que mostram o LD pautando a ação pedagógica, pela influência que ele possui na prática docente, pelos conteúdos estruturados e por oferecer uma proposta de ensino (SELLES; FERREIRA, 2004).

Outra dimensão do LD é a visão de ciência que é difundida por ele. Os pesquisadores possuem uma preocupação com a epistemologia que é apresentada pelos livros: "[...] ele não somente pauta a estruturação da disciplina de Física, bem como é a fonte dos enunciados sobre ciência, influenciando, portanto, de forma substancial, a construção das visões epistemológicas dos alunos" (LIMA; OSTERMANN; CAVALCANTI, 2017, p. 473). A crítica dos pesquisadores se baseia na presença de erros conceituais e históricos presentes nas obras. Essas análises tendem a mostrar uma transposição didática que simplifica e não traz aprofundamentos aos conteúdos e conceitos. Os LD abordam uma perspectiva da ciência que estaria longe do que os pesquisadores acreditam ser a necessária, visando uma alfabetização científica de alunos e professores que terão contato com o material. Uma das razões para isso, de acordo com Lima, Ostermann e Cavalcanti (2017, p. 454), é que os autores dos LD abordam os conteúdos do mesmo modo que aprenderam em suas formações acadêmicas, o que repercute uma visão positivista e tecnicista, "[...] silenciando discussões filosóficas e críticas em 
benefício de um ensino simplista, pragmatista e ingênuo". Assim, o LD e a formação de professores mantêm uma visão da ciência que repercute no ensino escolar e que implica diretamente na atuação do professor e na aprendizagem do aluno.

Nesse sentido, cabe problematizar a organização do PNLD tendo em vista as críticas apresentadas até aqui e os descompassos entre o que o programa recomenda e os usos que os professores fazem desse material. Os pesquisadores que se propõe a avaliar essa articulação identificam uma não linearidade entre o que demanda os documentos oficiais da educação, o que o PNLD oferece e os usos que são feitos (GRAMOWSKI; DELIZOICOV; MAESTRELLI, 2017, p. 14). São, em grande parte, professores vinculados às universidades que avaliam as coleções submetidas aos editais do PNLD, que, por sua vez, possuem como autoria professores do ensino superior (NICIOLI JUNIOR; MATTOS, 2016). Portanto, há uma relação, nem sempre nítida, entre as editoras, autores dos LD, e avaliadores. Além disso, existe um contraste entre o que os autores do LD produzem enquanto material didático, considerando a editora e o edital do PNLD, e o que área da educação em ciências produz como pesquisa (OLIVEIRA; ROSA, 2016).

Os artigos que analisamos sobre os LD investigam os conteúdos e usos dos livros, porém observamos poucas investigações propositivas, que desenvolvem alguma experiência ou ofertem uma abordagem diferente (GRAMOWSKI; DELIZOICOV; MAESTRELLI, 2017). Acreditamos que isso ocorre pela relevância pedagógica que o LD adquire no cenário escolar, ao tratar do currículo, da didática e da formação dos professores. Percebemos, também, que o LD é tratado de forma isolada, como único estruturante da atuação dos professores. Acreditamos que é pertinente entender esse material em relação à formação de professores e à produção de saberes da área, especialmente a subutilização do LD e a marginalização dos conhecimentos educacionais. A análise da emergência do livro didático na educação em ciências mostrou que existe um modo de investigação que prioriza críticas aos usos e conteúdos dos LD. Os autores apontam esse material como um estruturante da prática educacional e a sua relação com a formação de professores, com a reprodução de práticas, de visões da ciência, e de políticas educacionais. Esses elementos indicam um direcionamento para avaliar o LD e uma consideração menor para uma perspectiva mais contextualizada entre saberes pedagógicos e científicos.

\section{A emergência do discurso ambiental: a educação pela crise e a criticidade social}

Observarmos, com a análise dos dez artigos que tratam especificamente da temática ambiental, uma argumentação em torno de um estado de crise, concebida pela relação destrutiva do ser humano com o meio ambiente. A crise representa uma situação que prenuncia uma calamidade, um estado crítico, embora também seja o período em que ocorrem as reflexões, as avaliações, e tomada de decisões e ações visando mobilizar recursos para superar esse momento. A crise ambiental, nesse contexto, seria uma manifestação do processo de produção e acumulação de recursos no sistema econômico atual, que enxerga o lucro independentemente das mazelas associadas à exploração (LOUREIRO; LIMA, 2009). Essa linha argumentativa em torno da crise ambiental é um discurso recorrente nos artigos analisados. Ela é utilizada 
como justificativa para pensar o processo educacional: "[...] o atual desenvolvimento da ciência e da tecnologia e seus impactos socioambientais reforçam a importância de se adotar a perspectiva crítica na educação" (LOUREIRO; LIMA, 2009, p. 89). Essa opção argumentativa presente nos artigos analisados trata a crise ambiental como um efeito do modelo de desenvolvimento econômico, científico e tecnológico.

Todavia, é importante ressaltar que a ideia de crise não é unânime. Steven Pinker (PINKER, 2018), por exemplo, oferece um conjunto de argumentações a favor da razão, ciência e progresso, afirmando que a abordagem tecnocrática seria a solução dos problemas que enfrentamos e a que poderá guiar a humanidade para o progresso, inclusive para enfrentar os riscos que a própria ciência produz. A mesma intervenção antrópica que está rompendo com a capacidade do ambiente de se recuperar, também seria aquela que resolveria este problema na visão do autor. Essa perspectiva implica em uma visão parcial sobre os avanços conquistados pela ciência, por isso é importante pontuar que esse discurso precisa ser problematizado por diferentes razões, principalmente pela incapacidade da ciência de resolver seus próprios problemas, pela finitude dos recursos naturais do planeta e pelo uso desregrado dos mesmos pelo ser humano.

A Educação Ambiental (EA), de modo geral, se refere a um processo educativo que agrega as problemáticas ambientais na formação dos indivíduos e possui "[...] discursos polissêmicos e muitas vezes contraditórios, que vão desde perspectivas conservadoras a críticas/revolucionárias" (COSTA; ECHEVERRÍA; RIBEIRO, 2017, p. 804). Nesse sentido, identificamos ao menos duas concepções que relacionam o ensino com a temática ambiental nos discursos dos pesquisadores. A primeira objetiva estimular comportamentos que promovam a readaptação dos alunos em uma sociedade que enfrenta problemas ambientais, direcionando-os para uma relação mais ecológica (COSENZA et al., 2014). Essas práticas individualizam a relação que os alunos possuem com o meio ambiente e associam as mudanças de comportamento com as soluções para os problemas ambientais. Além disso, são caracterizadas por não possuir uma visão social mais sistêmica e uma ideia descontextualizada das questões econômicas e políticas. Essa simplificação da temática não problematiza os motivos dos problemas ambientais e as transformações não são abrangentes.

A outra concepção objetiva a transformação da ordem social por meio de uma perspectiva crítica. A crise ambiental estaria relacionada ao modo de desenvolvimento econômico capitalista e para superá-la seria necessária uma renovação social e no uso dos recursos. A EA crítica busca promover um processo permanente de conscientização das problemáticas ambientais para que os alunos adquiram conhecimentos que envolvam crenças e atitudes, visando a transformação social (COSENZA et al., 2014). Essa perspectiva, além de promover mudanças individuais, também se compromete com mudanças de valores e transformações mais profundas. Assim, essa posição da EA permitiria ao aluno a emancipação como cidadão ativo, que possui capacidade para entender e mudar o seu entorno. Os artigos analisados, por vezes, combinam essas concepções (COSTA; ECHEVERRÍA; RIBEIRO, 2017; LUCATTO; TALAMONI, 2007) ou apresentam apenas uma delas (MOROZESK; COELHO, 2016; PASIN; BOZELLI, 2017). Entretanto, a perspectiva crítica da EA ganha mais destaque, sendo um discurso recorrente dentre os pesquisadores. Inclusive se vinculando com outras abordagens do ensino de ciências, como a Ciência, Tecnologia e Sociedade (CTS) e Ambiente 
(CTSA), que seriam capazes de "[...] expor mazelas sociais e econômicas ligadas ao nosso modelo de desenvolvimento, explicitando suas dimensões ambientais, éticas, culturais e políticas" (LOUREIRO; LIMA, 2009, p. 93).

Nesse ponto de vista, a EA ganha uma abordagem que enfatiza a associação entre teoria e prática, proposta que não estaria presente na educação atualmente, de acordo com os artigos investigados. Ofertar uma oportunidade para que alunos e professores possam refletir sobre sua própria prática, aparece nos artigos como um aprendizado fundamental para essa transformação crítica argumentada pelos pesquisadores (CUNHA; LATINI, 2014). Essa abordagem de aproximar teoria e prática aparece como um dos eixos estruturantes da EA nos artigos analisados. Nesse sentido, o discurso que enfatiza a crise ambiental tenta mostrar que existe uma realidade a cerca dos problemas ambientais que pode ser percebida pelos estudantes. Essa concretude uniria uma dada realidade com a perspectiva científica e educacional, mostrando os meios possíveis para superar essas dificuldades (COSTA; LOUREIRO, 2015).

A EA e a interdisciplinaridade, no discurso dos pesquisadores, são tratadas como indissociáveis (LUCATTO; TALAMONI, 2007). A proposta interdisciplinar nesse contexto, "[...] caracteriza-se pelo enfoque científico e pedagógico que se estabelece por um diálogo entre especialistas de diversas áreas sobre uma determinada temática" (COSTA; LOUREIRO, 2015, p. 696). A argumentação dos autores, ao mesmo tempo que aproxima a EA e a interdisciplinaridade, mostra que em muitos casos ela possui um caráter mais normativo do que prático (VALDANHA NETO; KAWASAKI, 2015). A presença da EA nos documentos oficiais e currículos da educação em ciências é alvo de escrutino dos pesquisadores, principalmente os Parâmetros Curriculares Nacionais (PCN) e o Programa Nacional de Educação Ambiental (ProNEA). A EA aparece nos currículos como um tema transversal, com a intenção de aproximar as questões ambientais com as educacionais. Porém, os pesquisadores entendem que essa proposta é uma norma vazia, pois nos próprios documentos não há indicações mais concretas ou possibilidades de efetivar essa articulação (CAVALCANTI NETO; AMARAL, 2011). Um dos resultados aponta que a abordagem crítica é insuficiente devido à escassez de aspectos sociais e políticos nas orientações curriculares (CUNHA; LATINI, 2014; VALDANHA NETO; KAWASAKI, 2015). A EA é tratada de modo pouco incisivo, com uma abordagem predominantemente resolutiva e pragmática, se aproximando de uma concepção individualista. A EA na perspectiva crítica deve se afastar de uma pedagogia tradicional, segundo os pesquisadores, principalmente no tratamento dado aos conteúdos científicos e a relação com os sujeitos (CUNHA; LATINI, 2014).

A EA contribuiria para ampliar a consciência dos cidadãos, não se limitando a mudanças de atitudes em relação ao meio ambiente, mas com as transformações sociais para superação dessa crise (PASIN; BOZELLI, 2017). A EA, na perspectiva crítica, pensa a crise ambiental em função dos aspectos sociais, econômicos, culturais e políticos de uma sociedade capitalista e desigual. Diante disso, a educação se compromete com uma transformação da ordem social, visando um modelo sustentável a partir da emancipação e liberação dos indivíduos (COSENZA et al., 2014). É com essa abordagem que o engajamento e a sensibilização ganham destaque no discurso dos pesquisadores, como um mecanismo para atingir as transformações sociais pela EA. Nessa lógica, para que os alunos possam tomar decisões ante às questões ambientais precisam, além de serem alfabetizados cientificamente, também conscientes socialmente 
(MOROZESK; COELHO, 2016). Ganha destaque, portanto, as práticas que engajam alunos e professores para decidirem questões sociais e ambientais do seu entorno: "[...] a formação em EA só foi possível em função da perspectiva dos professores como sujeito da produção, um processo de mobilização, reflexão e ação" (LUCATTO; TALAMONI, 2007, p. 396). A abordagem EA é, nessa conjuntura, permeada por uma função social do ensino de ciências, com o objetivo de desenvolver atitudes e valores em uma perspectiva humanística (CUNHA; LATINI, 2014).

Portanto, é possível identificar pelo menos três momentos da EA enquanto prática pedagógica: sensibilizadora, contextualizadora e conscientizadora. A argumentação dos pesquisadores implica em uma transformação que não está associada à relação do ser humano com o meio ambiente, mas pela emancipação crítica dos indivíduos para agir na sociedade. Essas reivindicações fomentam a formação de valores éticos, morais e atitudes no ensino de ciências e na $E A$, ressignificando seus objetivos e práticas (LOUREIRO; LIMA, 2009). A temática ambiental aparece nessas propostas educacionais como um disparador para conscientizar, engajar e emancipar os alunos nesses valores e nas transformações sociais almejadas (CAVALCANTI NETO; AMARAL, 2011). Nesse cenário, o discurso de crise e da importância do meio ambiente são meios de tornar uma perspectiva pedagógica crítica possível para os sujeitos da educação. Essa proposta busca incluir outras dimensões para o ensino de ciências, como a social e cultural. Entendemos que com essa proposta os pesquisadores da EA propõem incluir a dimensão humana em uma visão demasiadamente científica sobre o meio ambiente, na tentativa de mitigar os problemas da sociedade contemporânea. "É importante superar essa percepção, ampliando-se concepções sobre o ambiente, de uma dimensão estritamente biológica para uma concepção que inclui as dimensões sociais e culturais, o mundo das humanidades" (CAVALCANTI NETO; AMARAL, 2011, p. 130).

Entendemos que, no discurso dos pesquisadores, transparece uma ideia de que a educação em ciências, quanto trata das questões ambientais, aborda os problemas de um ponto de vista científico, que se mostraria insuficiente para a complexidade das questões atuais. Assim, a proposta seria adicionar o mundo das humanidades nessa dimensão, e tratar da temática ambiental desde uma outra perspectiva. Com um olhar que enxerga a educação como uma prática transformadora, não somente para o modelo de desenvolvimento econômico e social, mas também para valores morais, éticos e de atitudes que, por consequência, impactarão no modo que os sujeitos pensam os recursos naturais e sua finitude.

\section{Considerações finais}

Desenvolvemos essa pesquisa a partir de um número restrito de artigos e exploramos três noções que são representativas da área de educação em ciências no Brasil. Com isso foi possível investigar a emergência dos mecanismos discursivos em torno dessas noções e os processos argumentativos utilizados pelos pesquisadores da área quando tratam da formação de professores, do livro didático ou da educação ambiental. O uso das redes semânticas como estratégia metodológica para adentrar no conjunto de artigos selecionados pelas palavras mais frequentes foi importante para tornar visível a conjuntura que envolve essas noções nos discursos dos autores. 
A ferramenta analítica desenvolvida foi fundamental para escrutinar as armações argumentativas utilizadas pelos pesquisadores, e nos guiar pelas ideias e conceitos presentes nos artigos.

A formação de professores é avaliada como insuficiente pelos pesquisadores e, por isso, os artigos apresentam diferentes propostas para melhorá-la. As relações entre teoria e prática, universidade e escola, saber científico e pedagógico representam uma força discursiva nos textos analisados. De acordo com os pesquisadores, o ethos acadêmico marginaliza os saberes pedagógicos na formação dos futuros professores, pois possui uma maior identificação com a pesquisa e menos com a docência. Além disso, a formação de professores ocorre entre duas instituições formativas (universidade e escola) que teriam objetivos diferentes, o que contribuiu para essa marginalização de um saber em detrimento de outro. A formação dos professores em ciências, conforme nossa análise, ocorre imbricada entre uma especialização científica, institucionalizada pela universidade, e uma pedagogia para ensinar conduzida pela escola.

Os LD estão sob constante avaliação dos pesquisadores, que identificam diferentes problemas, como a visão fragmentada do conhecimento, a subutilização pelos professores e as políticas públicas. Ainda assim, os LD são considerados componentes estruturantes da educação escolar, pois oferecem uma proposta de ensino e sustentam uma formação de professores pela prática em sala de aula. Percebemos um direcionamento das pesquisas em educação em ciências em avaliar os conteúdos científicos dos LD e as implicações na formação de professores e uma menor atenção para os efeitos que essa imbricação entre ciência e educação, materializada no LD, repercute na área. A Educação Ambiental é uma área emergente na educação em ciências, principalmente por analisar os efeitos da ciência e da tecnologia na sociedade. A argumentação dos pesquisadores da EA se sustenta em torno da crise ambiental e da busca por uma criticidade social. O discurso dos autores fomenta uma transformação de comportamentos e valores como um meio para conscientizar os sujeitos em uma perspectiva crítica. Entendemos que nessa prática discursiva existe uma tentativa de incluir a dimensão humana e social na área da educação em ciências, o que implicaria repensar uma área do conhecimento com uma visão demasiadamente científica.

A análise das três noções mostrou a existência de um estranhamento no discurso dos pesquisadores, como se cotejassem o papel da pedagogia na educação em ciências. A tentativa de humanizar a ciência a partir da temática ambiental indica uma zona de enfrentamento a uma visão cientificista da área. As pesquisas analisadas sugerem que os saberes educacionais estão ausentes em grande parte das problemáticas do ensino de ciências que tratam dessas noções. As problematizações que estão sendo adicionadas pelos pesquisadores em ensino de ciências são influenciadas, sobretudo, pela presença do discurso pedagógico. Nesse sentido, o discurso dos pesquisadores visa promover a inserção dos saberes educacionais para preencher essas ausências na área.

\section{Agradecimentos}

Este trabalho foi financiado pela Fundação de Amparo à Pesquisa do Estado de São Paulo (FAPESP) por meio dos processos 2015/21926-4 e 2017/07630-0. 


\section{Referências}

ABIB, M. L. V. S.; MURILLO, F. J.; LOURENÇO, A. B. Aprendendo a ensinar e a argumentar: saberes de argumentação docente na formação de futuros professores de química. Revista Brasileira de Pesquisa em Educação em Ciências, Belo Horizonte, v. 16, n. 2, p. 295-316, 2016. Disponível em: https://bit.ly/3gBjmZw. Acesso em: 1 jun. 2021.

BOURDIEU, P. Usos sociais da ciência: por uma sociologia clínica do campo científico. São Paulo: Ed. UNESP, 2004.

BRAGA, S. A. M.; MORTIMER, E. F. Os gêneros de discurso do texto de biologia dos livros didáticos de ciências. Revista Brasileira de Pesquisa em Educação em Ciências, Belo Horizonte, v. 3, n. 3, p. 56-74, 2003. Disponível em: https://bit.ly/3cGASdH. Acesso em: 1 jun. 2021.

CAVALCANTI NETO, A. L. G.; AMARAL, E. M. R. Ensino de ciências e educação ambiental no nível fundamental: análise de algumas estratégias didáticas. Ciência \& Educação, Bauru, v. 17, n. 1, p. 129-144, 2011. DOI: https://doi.org/c33sf8.

CHRISTINO, V. C. L.; FERREIRA, M. Formação de professores, discursos e práticas de ingressantes na docência em química na educação básica. Acta Scientiae, Canoas, v. 15, n. 1, p. 172-190, jul. 2013. Disponível em: https://bit.ly/3xgd740. Acesso em: 1 jun. 2021.

COSENZA, A.; FREIRE, L. M.; ESPINET, M.; MARTINS, I. Relações entre justiça ambiental, ensino de ciências e cidadania em construções discursivas docentes. Revista Brasileira de Pesquisa em Educação em Ciências, Belo Horizonte, v. 14, n. 2, p. 89-98, 2014. Disponível em: https://bit. ly/3pZyDYv. Acesso em: 1 jun. 2021.

COSTA, C. A. S.; LOUREIRO, C. F. B. Interdisciplinaridade e educação ambiental crítica: questões epistemológicas a partir do materialismo histórico-dialético. Ciência \& Educação, Bauru, v. 21, n. 3, p. 69-708, 2015. DOI: https://doi.org/ghwt.

COSTA, L. S. O.; ECHEVERRÍA, A. R.; RIBEIRO, F. L. O processo de tomada de consciência e a formação de conceitos da educação ambiental na formação inicial de professores de ciências/ química. Revista Brasileira de Pesquisa em Educação em Ciências, Belo Horizonte, v. 17, n. 3, p. 803834, 2017. Disponível em: https://bit.ly/3zresab. Acesso em: 1 jun. 2021.

CRUZ, E. P.; BARZANO, M. A. L. Saberes docentes: um olhar para uma dimensão não exigida nas trajetórias de professores-pesquisadores do curso de licenciatura em ciências biológicas. Investigações em Ensino de Ciências, Porto Alegre, v. 19, n. 1, p. 117-139, 2014. Disponível em: https://bit.ly/2SqaloZ. Acesso em: 1 jun. 2021.

CUNHA, A. S.; LATINI, R. M. Pesquisa participante como abordagem metodológica no ensino aprendizado de matemática e educação ambiental. Investigações em Ensino de Ciências, Porto Alegre, v. 19, n. 2, p. 323-341, 2014. Disponível em: https://bit.ly/2U6ABKT. Acesso em: 1 jun. 2021.

FIORENTINI, D. A pesquisa e as práticas de formação de professores de matemática em face das políticas públicas no Brasil. Bolema: boletim de educação matemática, Rio Claro, v. 21, n. 29, p. 43-70, 2008. Disponível em: https://bit.ly/3wnPg2o. Acesso em: 1 jun. 2021.

FOUCAULT, M. A ordem do discurso: aula inaugural no Collège de France, pronunciada em 2 de dezembro de 1970. 24. ed. São Paulo: Loyola, 2012.

FOUCAULT, M. A arqueologia do saber. 8. ed. Rio de Janeiro: Forense Universitária, 2013. .

GRAMOWSKI, V. B.; DELIZOICOV, N. C.; MAESTRELLI, S. R. P. O PNLD e os guias dos livros didáticos de ciências (1999-2014): uma análise possível. Ensaio: pesquisa em educação em ciências, Belo Horizonte, v. 19, n. e2571, p. 1-18, 2017. DOI: https://doi.org/ghwv. 
LIMA, N. W.; OSTERMANN, F.; CAVALCANTI, C. J. H. Física quântica no ensino médio: uma análise bakhtiniana de enunciados em livros didáticos de física aprovados no PNLDEM 2015. Caderno Brasileiro de Ensino de Física, Florianópolis, v. 34, n. 2, p. 435-459, 2017. DOI: https://doi.org/ ggwp6q.

LOUREIRO, C. F. B.; LIMA, J. G. S. Educação ambiental e educação científica na perspectiva ciência, tecnologia e sociedade (CTS): pilares para uma educação crítica. Acta Scientiae, Canoas, v. 11, n. 1, p. 88-100, 2009. Disponível em: https://bit.ly/3pQyOoW. Acesso em: 1 jun. 2021.

LUCATTO, L. G.; TALAMONI, J. L. B. A construção coletiva interdisciplinar em educação ambiental no ensino médio: a microbacia hidrográfica do Ribeirão dos Peixes como tema gerador. Ciência \& Educação, Bauru, v. 13, n. 3, p. 389-398, 2007. DOI: https://doi.org/bgmsxv.

MAGALHÃES JÚNIOR, C. A. O.; TOMANIK, E. A.; CARVALHO, G. S. Análise da transposição didática na formação continuada sobre meio ambiente de professores do ensino fundamental. Revista Brasileira de Pesquisa em Educação em Ciências, Belo Horizonte, v. 16, n. 2, p. 237-256, 2016. Disponível em: https://bit.ly/3wsE2tq. Acesso em: 1 jun. 2021.

MASSENA, E. P.; SIQUEIRA, M. R. P. Contribuições do PIBID à formação inicial de professores de ciências na perspectiva dos licenciandos. Revista Brasileira de Pesquisa em Educação em Ciências, Belo Horizonte, v. 16, n. 1, p. 17-34, 2016. Disponível em: https://bit.ly/3zpKMKG. Acesso em: 1 jun. 2021.

MOROZESK, M.; COELHO, G. R. Lixo eletrônico "uso e descarte": uma proposta de intervenção em uma Escola Pública de Vitória-ES. Revista Brasileira de Pesquisa em Educação em Ciências, Belo Horizonte, v. 16, n. 2, p. 317-338, 2016. Disponível em: https://bit.ly/3iH0oUi. Acesso em: 1 jun. 2021.

NICIOLI JUNIOR, R. B.; MATTOS, C. R. A disciplina e o conteúdo de cinemática nos livros didáticos de física do Brasil (1801 a 1930). Investigações em Ensino de Ciências, Porto Alegre, v. 13, n. 3, p. 275-298, 2016. Disponível em: https://bit.ly/35yqZet. Acesso em: 1 jun. 2021.

OLIVEIRA, A. C. G.; ROSA, M. I. P. Recontextualizações e hibridismos em processos de elaboração e avaliação de livros didáticos de química. Química Nova na Escola, São Paulo, v. 38, n. 3, p. 273283, 2016. Disponível em: https://cutt.ly/Pmht0gP. Acesso em: 2 jul. 2021.

PASIN, E. B.; BOZELLI, R. L. Sentidos de educação ambiental mobilizados em discursos de professores de escolas envolvidos na formação de licenciandos em ciências biológicas. Investigações em Ensino de Ciências, Porto Alegre, v. 22, n. 2, p. 33-56, 2017. DOI: https://doi.org/ ghwx.

PINKER, S. O novo iluminismo: em defesa da razão, da ciência e do humanismo. São Paulo: Companhia das Letras, 2018.

R CORE TEAM. R: a language and environment for statistical computing. Vienna, Austria, 2018. Disponível em: http://www.r-project.org/index.html. Acesso em: 15 jun. 2021.

REIS, D. B.; ALBUQUERQUE, T. S.; SOARES, M. R. A. As leishmanioses e o livro didático: como as doenças endêmicas são abordadas no ensino publico? Investigações em Ensino de Ciências, Porto Alegre, v. 19, n. 1, p. 91-98, 2014. Disponível em: https://bit.ly/3iFeGEl. Acesso em: 1 jun. 2021.

ROSA, M. G. Modelo empírico para analisar a robustez de redes semânticas. Salvador: UFBA, 2016.

SCHIRMER, S. B.; SAUERWEIN, I. P. S. Livros didáticos em publicações na área de ensino: contribuições para análise e escolha. Investigações em Ensino de Ciências, Porto Alegre, v. 22, n. 1, p. 23-41, 2017. DOI: https://doi.org/ghwz.

SCHNORR, S. M. Do encontro entre os discursos científico e pedagógico: uma investigação sobre os periódicos brasileiros de educação em ciências (1994-2018). 2019. 214 f. Tese (Doutorado em Educação Científica, Matemática e Tecnológica) - Faculdade de Educação, Universidade de São Paulo, São Paulo, 2019. 
SELLES, S. E.; FERREIRA, M. S. Influências histórico-culturais nas representações sobre as estações do ano em livros didáticos de ciências. Ciência \& Educação, Bauru, v. 10, n. 1, p. 101-110, 2004. DOI: https://doi.org/b4v5w6.

SILVA, P. S. A.; CHAVES, S. N. Epistemologia, ética e política na formação de professores de ciências. Ensaio: pesquisa em educação em ciências, Belo Horizonte, v. 11, n. 2, p. 259-276, 2009. DOI: https://doi.org/ghw2.

SILVEIRA, F. P. R. DE A. A aprendizagem significativa na formação de professores de biologia: o uso de mapas conceituais. Revista Brasileira de Pesquisa em Educação em Ciências, Belo Horizonte, v. 4, n. 3, p. 29-40, 2004.

TEIXEIRA, G. M.; AGUIAR, M. S. F.; CARVALHO, C. F.; DANTAS, D. R.; CUNHA, M. V.; MORAIS, J. H. M.; PEREIRA, H. B. B.; MIRANDA, G. V. Complex semantic networks. International Journal of Modern Physics C, Singapore, v. 21, n. 3, p. 333-347, 2010. DOI: https://doi.org/bq6x3n.

VALDANHA NETO, D.; KAWASAKI, C. S. A temática ambiental em documentos curriculares nacionais do ensino médio. Ensaio: pesquisa em educação em ciências, Belo Horizonte, v. 17, n. 2, p. 483-499, 2015. DOI: https://doi.org/gg2sq9.

VIANNA, D. M.; CARVALHO, A. M. P. Do fazer ao ensinar ciência: a importância dos episódios de pesquisa na formação de professores. Investigações em Ensino de Ciências, Porto Alegre, v. 6, n. 2, p. 111-132, 2001. Disponível em: https://bit.ly/3wC9cyV. Acesso em: 1 jun. 2021.

VILANOVA, R. Educação em ciências e cidadania: mudança discursiva e modos de regulação na política do Programa Nacional do Livro Didático. Ciência \& Educação, Bauru, v. 21, n. 1, p. 177-197, 2015. DOI: https://doi.org/ghw3.

VILLANI, A.; BAROLLI, E.; MAIA, J. O.; MASSI, L.; SANTOS, V. F. D.; NASCIMENTO, W. E. Mestrados profissionais em ensino de ciências: estrutura, especificidade, efetividade e desenvolvimento profissional docente. Investigações em Ensino de Ciências, Porto Alegre, v. 22, n. 1, p. 127-161, 2017. DOI: https://doi.org/ghw4.

ZAMBON, L. B.; TERRAZZAN, E. A. Livros didáticos de física e sua (sub)utilização no ensino médio. Ensaio: pesquisa em educação em ciências, Belo Horizonte, v. 19, n. e2668, p. 1-22, 2017. DOI: https://doi.org/gg2sgb. 